Journal of

Accident and

Emergency

Medicine 1995

12, 49-51

\title{
Dangerous monoamine oxidase inhibitor interactions are still occurring in the 1990s
}

\author{
J.K. DAWSON, ${ }^{1}$ S.M.EARNSHAW ${ }^{2}$ \& C.S.GRAHAM ${ }^{1}$ \\ 1 St Helens and Knowsley Hospitals, Warrington Road, Prescot, Merseyside, ${ }^{2}$ Olive Mount Hospital, Old Mill \\ Lane, Liverpool
}

\section{SUMMARY}

The clinical course is described of a 28-year-old woman who was severely ill following ingestion of a Do-Do tablet (which consists of ephedrine, caffeine and theophylline), $24 \mathrm{~h}$ after discontinuing phenelzine treatment. Signs and symptoms were delayed for $8 \mathrm{~h}$ after which she developed encephalopathy, neuromuscular irritability, hypotension, sinus tachycardia, rhabdomyolysis and hyperthermia. Her illness was complicated by pneumonia and adult respiratory distress syndrome (ARDS). The management of monoamine oxidase inhibitor (MAOI) toxicity, which can arise from interactions and overdoses, is discussed. It should be remembered that, despite the increase in use of alternative and safer antidepressants, MAOI interactions still occur and unless they are managed appropriately, are potentially fatal. Patients need to be warned that restrictions apply for up to 2 weeks after stopping the medication, and doctors need to be aware that serious interactions can occur in this time period.

Key words: Interactions, monoamine oxidase inhibitors, phenelzine, rhabdomyolysis, toxicity.

\section{INTRODUCTION}

Monoamine oxidase inhibitor interactions are well recognized and occasionally life threatening. However, they are now so uncommon that many doctors will not have experienced a case. It is surprisingly difficult to find guidelines on how to treat the complications that may arise. We report a case of near fatal drug interaction with phenelzine and ephedrine and discuss the management options.

Correspondence:

J.K. Dawson,

Medical Registrar, St Helens and Knowsley Hospitals, Warrington Road, Prescot,

Merseyside L35 5DR, UK. whilst at a parents evening. The only history given at that time was that she had recently taken a 'DoDo' tablet for a 'wheezy cough'.

Initial examination revealed her to be flushed and agitated, but coherent with a temperature of $37^{\circ} \mathrm{C}$. She had a pulse rate of 150 beats $\min ^{-1}$ and a blood pressure of $90 / 60 \mathrm{mmHg}$. Chest examination revealed widespread wheeze.

It was thought that she was suffering from anaphylactic shock and was treated with $100 \mathrm{mg}$ of intravenous hydrocortisone and $500 \mathrm{~mL}$ of haemaccel. Her blood pressure then returned to normal but there was no effect on her other symptoms. The following history emerged only after close questioning of the patient and her relatives. She had been becoming increasingly 'chesty' over the last 2 days and had taken 1 'Do-Do' tablet (containing $30 \mathrm{mg}$ of caffeine, $18.31 \mathrm{mg}$ of ephedrine hydrochloride and $100 \mathrm{mg}$ of theophylline) $8 \mathrm{~h}$ earlier. She had abruptly stopped taking phenelzine $60 \mathrm{mg}^{\text {day }}{ }^{-1}$ the previous day, as the tablets had run out. She had been taking these regularly for 4 weeks. They had been prescribed for an atypical depression, occurring post-hysterectomy, by a consultant psychiatrist. She had a past history of asthma treated only with a salbutamol inhaler. Repeat examination $30 \mathrm{~min}$ later revealed her to have a tachycardia of $150 \mathrm{~min}^{-1}$ and a blood pressure of $120 / 80 \mathrm{mmHg}$ but no other cardiovascular abnormality. Her temperature was unchanged. She was severely agitated with dilated pupils, increased muscle tone and hyperreflexia but no focal deficit. There were no specific features suggestive of thyrotoxicosis, or intravenous drug abuse.

At this point MAOI interaction as a result of ephedrine consumption, was felt to be the most likely diagnosis. As agitation was the main problem she was treated with intravenous diazepam. This in fact worsened her mental state, she developed visual hallucinations and was no longer coherent. Chlormethiazole intravenously had no effect. Elective

(C) 1995 Blackwell Science Ltd 
J.K. Dawson et al.

ventilation and treatment with non-depolarizing muscle relaxants was used to control the agitation and neuromuscular irritability. Over the next $4 \mathrm{~h}$ she developed a pyrexia of $39^{\circ} \mathrm{C}$.

Subsequent investigations revealed no evidence of drug overdose or misuse. There was a marked rise in creatinine kinase to $29370 \mathrm{iuL}^{-1}$ over the following $24 \mathrm{~h}$, and myoglobin was detected in her urine, presumably as a result of the rhabdomyolysis. In view of this she was treated with $4 \mathrm{~L} \mathrm{day}^{-1}$ of intravenous fluid, and her renal function remained normal. Hypertension did not ensue and she remained in sinus rhythm.

Her illness was complicated by the development of a lobar pneumonia and adult respiratory distress syndrome which resulted in ventilation for a further 17 days; during which time she became colonized by methicillin resistant staphylococcus aureus. She was discharged from hospital after a total stay of 3 weeks. There was no permanent neurological damage but respiratory function was impaired on pulmonary function testing, as would be expected on recovery from adult respiratory distress syndrome.

\section{DISCUSSION}

Monoamine oxidase inhibitors are now generally regarded as a second line therapy in major depression, principally because of their interactions, side effects and unfavourable reports on efficacy. ${ }^{1}$ They tend to be reserved for resistant depression (alone or in combination) or atypical depression i.e. depression with reversed biological features. They are still favoured by some clinicians and there are approximately $\mathbf{2 6 0 0 0}$ prescriptions issued for Nardil each year. ${ }^{2}$

The hypertensive interactions are well described and clinicians are aware of the need to inform patients of dietary restrictions and drug interactions. However, what may be poorly emphasized is the need for continued vigilance for at least two weeks after stopping monoamine oxidase inhibitors; and the potentially fatal consequence of an interaction with indirect amines. This patient had been well informed of the foods she should avoid and told not to take any other medication whilst on phenelzine. Unfortunately, it was not stressed that this instruction applied for at least 2 weeks after stopping the medication.

'Do-Do' tablets are 'over the counter' preparations advertised to the public as being a relief for 'bronchial coughs', wheezing and breathlessness; being aware of the interactions of theopylline, the phar- macist dispensing the tablets asked whether she was taking any medication but she felt it to be of no relevance to mention that she had stopped taking phenelzine the previous day. This case demonstrates the importance of taking a comprehensive drug history, which should include 'over the counter' preparations. But more importantly it emphasizes the need to inform patients on irreversible, nonspecific MAOI that the restrictions apply for at least 2 weeks after cessation of therapy. ${ }^{3}$

It has been suggested that MAOI have an enhanced effect in patients who are slow acetylators. ${ }^{4}$ It is therefore possible that this patient developed a severe adverse reaction with a relatively small quantity of ephedrine because she has a slow acetylator status. It is interesting to note the similarities between MAOI interactions and malignant hyperthermia and it is possible that the caffeine and theophyline (both being methylxanthines) contributed to the clinical syndrome that developed. The cause of malignant hyperthermia is unknown but there are abnormalities in the response of the muscles of affected individuals to caffeine in vitro. ${ }^{5}$

\section{MANAGEMENT OF MAOI TOXICITY}

The features of MAOI toxicity that may be seen with drug interactions or overdosage are: hypertension or hypotension, tachycardia, arrhythmias, hypothermia, hyperthermia and malignant hyperpyrexia, agitation and hallucinations, hyper-reflexia, convulsions and spasticity, urinary retention, rhabdomyolysis, disseminated intravascular coagulation and acute tubular necrosis. Special care should be observed with any drug used in the management of monoamine oxidase inhibitor toxicity in view of the many known interactions which occur with this class of drugs. $^{6}$

(1) Hypertension is best controlled with slow intravenous injection of $5 \mathrm{mg}$ of phentolamine, mild to moderate hypertension may be treated with sublingual nifedipine.

(2) Hypotension should initially be treated with intravenous fluids. If this fails to produce an adequate response in association with severe hypotension then cautious use of directly acting sympathomimetics such as noradrenaline is suggested. ${ }^{7}$ it should always be remembered that their effects will be enhanced and they should be used with intensive monitoring facilities.

(3) Hyperpyrexia may respond to paracetamol and external cooling. If the rectal temperature 
Dangerous monoamine oxidase inhibitor interactions exceeds $39^{\circ} \mathrm{C}$ then the trachea should be intubated and the patient given a neuromuscular blocking agent, such as atracurium. If this fails to control the temperature then dantrolene can be used.

(4) Agitation should initially be treated with diazepam, this is a safe first time treatment. Chlorpromazine may be used which will have a beneficial effect on hyperpyrexia and hypertension but several authorities discourage its use, as it may be complicated by coma, hypotension and cardiac arrest. ${ }^{8,9}$ In severe cases of neuromuscular irritability patients may require the use of muscle relaxants and intubation with assisted ventilation.

(5) Seizures should be treated with phenytoin.

(6) Arrhythmias are difficult to treat, ${ }^{10}$ and they are often a preterminal sign. Supraventricular dysrhythmias, unless causing hypotension, can be managed conservatively with careful observation. Beta blockers are often effective but should be used cautiously to avoid unopposed alpha-adrenergic stimulation. Digoxin can be used but digoxin toxicity is enhanced by monoamine oxidase inhibitors and clinicians should observe for this. Ventricular arrhythmias should be managed with lignocaine, procainamide or phenytoin. Bretylium is contraindicated because of its pharmacological similarities to monoamine oxidase inhibitors. Atropine, isoprenaline and temporary pacing may be used to treat bradyarrythmias. Isoprenaline should be used in lower than usual dosages because monoamine oxidase inhibition may result in exaggerated responses to sympathomimetic agents.

\section{CONCLUSION}

There is a real risk that those who are unfamiliar with monoamine oxidase inhibitors may underestimate the risks associated with them. With the introduction of new classes of anti-depressants, which now include selective reversible monoamine oxidase inhibitors, we hope that clinicians will consider all their options, both pharmacological and psychological, before embarking on treatment with hazardous medication.

We feel that MAOI should be prescribed by psy- chiatrists who are experienced with their use and then only for valid indications. Patients and general practitioners need clear and comprehensive guidelines about the precautions involved in taking MAOls. Patients should be supplied with warning cards, such as those prepared jointly by the Pharmaceutical Society and British Medical Association for the Department of Health. This case demonstrates that clinicians still need to be aware of the signs, symptoms and treatment of monoamine oxidase inhibitor toxicity.

\section{REFERENCES}

1. Medical Research Council (1965) Clinical trial of the treatment of depressive illness. British Medical Journal 1, 831-836.

2. Personal communication, Parke Davies \& Co Ltd.

3. Grahame-Smith D.G. \& Aronson J.K. (1988) Oxford Textbook of Clinical Pharmacology and Drug Therapy, pp. 709-712. Oxford University Press, Oxford.

4. Marshall E.F., Mountjoy C.Q., Campbell I.C. et al. (1978) The influence of acctylator phenotype on the outcome of treatment with phenelzine, in a clinical trial. British Journal of Clinical Pharmacology 6, 247, 1978.

5. Kalow W., Britt B.A., Terreau M.E. \& Haist B.A. (1970) Metabolic error of muscle metabolism after recovery from malignant hyperthermia. Lancet 2, 895-898.

6. Reynolds J.E.F. (1993) Martindale: The Extra Pharmacopoeia (30th edn), pp. 267-267. Pharmaceutical Press, London.

7. Linden C.H., Rumack B.H. \& Strehlke C. (1984) Monoamine oxidase inhibitor overdose. Annals of Emergency Medicine 13, 1137-1144.

8. Robertson J.C. (1972) Recovery after massive MAOI overdose complicated by malignant hyperpyrexia, treated with chlorpromazine. Postgraduate Medical Journal 48, 64-65.

9. Ciocatto E., Fagiano G. \& Bava G.L. (1972) Clinical features and treatment of overdosage of monoamine oxidase inhibitors and their interaction with other psychotropic drugs. Resuscitation 1, 69-72.

10. Haddad L.M. \& Winchester J.F. (1990) Clinical Management of Poisoning and Drug Overdose (2nd edn), pp. 793-798. W.B. Saunders Co., Philadelphia. 